\title{
A vueltas con la objeción de conciencia de los farmacéuticos comunitarios
}

\section{José Javier Ordóñez Echeverría}

Abogado y filósofo. Colaborador del Institut Borja de Bioètica y miembro del Comité Ético Asistencial del Hospital Sant Joan de Déu de Esplugues de Llobregat (Barcelona).

\section{PALABRAS CLAVE}

Objeción de conciencia, libertad ideológica, farmacia comunitaria, píldora postcoital, desobediencia civil

\section{KEYWORDS}

Conscientious objection, ideological freedom, community pharmacy, morning-after pill, civil disobediencel

\section{RESUMEN}

La sentencia del Pleno del Tribunal Constitucional del 25 de junio de 2015 ha provocado que se coloque de nuevo en el debate público la cuestión de la objeción de conciencia en las profesiones sanitarias. En 2010, año de la aprobación de la Ley 2/2010, de salud sexual y reproductiva, éste había sido ya un tema de amplia discusión. En este comentario nos proponemos exponer los problemas éticos y jurídicos fundamentales que plantea el recurso de amparo, los argumentos principales que refleja la sentencia y que, a nuestro juicio, son relevantes para la bioética y tratar de fijar cuáles son los avances o retrocesos que en la cuestión bioética de la objeción de conciencia de los profesionales sanitarios aporta esta resolución judicial.

Struggling with the conscientious objections of community pharmacists

\section{ABSTRACT}

The ruling of the plenary session of the constitutional tribunal of June 25, 2015 once again brought the question of conscientious objection in the healthcare profession into public debate. This was a subject of considerable discussion in 2010, when Law 2/2010 regarding sexual and reproductive health was approved. In this article we attempt to illustrate the fundamental ethical and legal problems presented by this appeal on the grounds of unconstitutionality and the main arguments in the judgment that are, in our opinion, relevant to bioethics. We also attempt to identify the advances or setbacks of this legal ruling with regard to bioethics of the conscientious objection of the healthcare professionals.
Recibido: $24 / 3 / 2016$

Aceptado: 28/5/2016

Disponible online: 1-6-2016
Financiación: Ninguna ajena al autor.

Conflicto de intereses: El autor declara no existir conflicto de intereses en relación con el contenido del artículo.

Cite este artículo como: Ordóñez JJ. A vueltas con la objeción de conciencia de los farmacéuticos comunitarios. Farmacéuticos Comunitarios. 2016 Jun 30; 8(2):24-27. doi:10.5672/FC.2173-9218. (2016/Nol8).002.04

Correspondencia: joecheve@icab.cat

ISSN 1885-8619 @SEFAC (Sociedad Española de Farmacia Familiar y Comunitaria). Todos los derechos reservados. 
En un Estado de Derecho, los ciudadanos estamos sujetos al cumplimiento de las leyes, que nos imponen deberes jurídicos que debemos respetar. Sin embargo, esta premisa debe ser compatible con una sociedad plural, en que conviven personas de diferentes ideologías, creencias y valores, y para quienes el sometimiento a esos deberes puede conllevar conflictos de conciencia y de moral personal. En consecuencia, la objeción de conciencia puede generar incumplimiento de los deberes legales de forma que limite el derecho de otro $\mathrm{y}$ genere un perjuicio para un tercero o, lo que puede ser más importante, para la comunidad en su conjunto. En bioética, la objeción de conciencia se ha estudiado en relación con el conflicto de derechos entre el profesional sanitario y el paciente. La legislación y la intervención de los poderes públicos que la legislación consagra han resuelto algunos dilemas éticos, pero otros siguen abiertos al debate. Así, el rechazo a tratamiento se puede leer en clave de una objeción de conciencia del paciente.

En síntesis, la sentencia del Pleno del Tribunal Constitucional del 25 de junio de 2015 [1], en relación con la Ley 2/2010 de salud sexual y reproductiva [2], que analizamos ahora resuelve un amparo que solicitó un farmacéutico de Sevilla alegando el derecho de objeción de conciencia a no disponer, en el establecimiento del que es cotitular, de existencias de píldora postcoital ni de preservativos. Dicha Ley, en su artículo 19.2, reconoce la objeción de conciencia a los profesionales sanitarios que intervengan directamente en un aborto. La Junta de Andalucía le sancionó con una multa de 3.300 euros por una infracción grave a la ley de Farmacia de Andalucía y al decreto que regula las existencias mínimas de medicamentos y productos sanitarios en las farmacias. La sentencia otorga finalmente el amparo al demandante, en lo que respecta solamente a la píldora postcoital, pero no en lo que respecta a los preservativos.

El farmacéutico opinaba que la imposición de la multa había vulnerado su derecho a la objeción de conciencia, como manifestación de la libertad ideológica reconocida en el art. 16.1 de la Constitución Española. Defendía que había sido sancionado por actuar en el ejercicio de su profesión de farmacéutico siguiendo sus convicciones éticas, que son contrarias a la dispensación de los medicamentos con el principio activo levonorgestrel 0,750 mg, debido a que los considera un abortivo precoz o incipiente que elimina la vida humana al impedir la anidación del embrión, según manifestaba en su recurso. También consideraba productos inmorales los preservativos y su dispensación traicionaba igualmente sus más arraigadas creencias.

Pues bien, las cuestiones analizadas por los magistrados del Tribunal Constitucional, en la sentencia y en los votos particulares, nos provocan las siguientes cinco grandes cuestiones:

\section{1. ¿Qué es la objeción de} conciencia? ¿Es necesaria, o no, una ley previa que regule el ejercicio de la objeción?

La objeción de conciencia no es un derecho fundamental, aunque se funda en la libertad ideológica y es una de sus manifestaciones. Por eso, ante derechos fundamentales, el de objeción de conciencia no tiene preeminencia sobre estos. Ésta es la opinión de las sentencias del Tribunal Constitucional desde 1982 y del Tribunal Supremo desde 2009. Y del Tribunal Europeo de Derechos Humanos en una decisión de 2001, que rechazó la demanda formulada por dos farmacéuticos franceses que se negaban a suministrar productos contraceptivos compuestos de estrógenos, al entender el Tribunal que el farmacéutico no puede imponer a otro sus convicciones religiosas para denegar la dispensación de un producto o medicamento.

El Tribunal Constitucional en la sentencia que analizamos ahora recoge una expresión de otra de sus sentencias de 1985, que afirmaba que el derecho a la objeción de conciencia existe y puede ser ejercido con independencia de que se haya dictado o no una regulación que lo reconozca en supuestos concretos. Sin embargo, la postura bioética más coincidente es que el derecho a la objeción de conciencia debe tender lógicamente a su reconocimiento jurídico. Y este reconocimiento no puede consistir en una regulación general o genérica de la objeción de conciencia en determinados colectivos profesionales, sino que la regulación debe centrarse sólo en cuestiones específicas, que presenten una clara dimensión ética, y debe precisar los escenarios concretos y los requisitos exigibles.

Y en el caso de la objeción de conciencia del farmacéutico sevillano, no existe una regulación previa acerca del alcance y condiciones de ejercicio, no hay precisión sobre los escenarios concretos y los requisitos exigibles de ese derecho objetor. Sin embargo, el farmacéutico estaba inscrito como objetor de conciencia en un registro llevado por el Colegio Oficial de Farmacéuticos de Sevilla. Y el derecho a la objeción de conciencia está reconocido en los Estatutos de dicho colegio profesional y en el Código de Ética Farmacéutica y Deontología de la Profesión Farmacéutica. El Tribunal Constitucional refleja la relevancia del reconocimiento colegial y estatutario de la objeción de conciencia, pues concluye que el farmacéutico "actuó bajo la legítima confianza de ejercitar un derecho, cuyo reconocimiento estatutario no fue objetado por la Administración".

En definitiva, permite objetar a los farmacéuticos por motivos de conciencia sin necesidad de una previa regulación por parte del legislador del ejercicio de esa objeción. 0 , al menos, sin una previa regulación con rango de ley. Lo que hace el Tribunal Constitucional es elevar la regulación colegial y estatutaria a un rango equivalente al legal. Este es un asunto novedoso aunque no exento de dificultades y pone de manifiesto la importancia que la autorregulación bioética de las profesiones sanitarias tiene para el Tribunal Constitucional. Esta interpretación constitucional es innegablemente expansiva de la objeción de conciencia y puede revolucionar el futuro Derecho sanitario.

\section{2. ¿La objeción de conciencia} ampara la negativa a disponer de medicamentos por la farmacia o más bien ampara la negativa a dispensarlos por un profesional farmacéutico concreto?

El Tribunal Constitucional analiza la objeción de conciencia de los farmacéuticos que desempeñan su profesión en farmacias, en particular respecto de la dispensación de medicamentos con posibles efectos 
abortivos y respecto de la obligación de disponer del mínimo de existencias de esos medicamentos que les impone la normativa.

Aunque el Tribunal no distingue con todo el rigor que consideramos debiera haberlo hecho, una cosa es la negativa a la dispensación del medicamento por parte del farmacéutico, como persona profesional y otra la falta de existencias mínimas en el establecimiento farmacéutico. En verdad, lo segundo fue lo sancionado por la Junta de Andalucía, lo primero no lo fue. Hay argumentos sólidos para aceptar la objeción de conciencia del profesional al dispensar, pero no tantos para asumir ese presunto derecho de una farmacia a no disponer.

La farmacia no es sujeto del derecho a la objeción, sino el profesional farmacéutico; la objeción es un derecho subjetivo de la persona física, no de una persona jurídica o de una empresa, como es una farmacia. El Tribunal ampara al particular en su derecho a no dispensar la píldora postcoital, pero omite pronunciarse sobre el derecho a objetar la disponibilidad de existencias por parte del establecimiento.

\section{3. ¿Cómo debemos resolver el} conflicto entre la objeción de conciencia del farmacéutico con el derecho de protección de la salud de quien requiere el medicamento?

La obligación de proveerse de las mínimas existencias de medicamentos es un deber legal en diversas normas estatales y autonómicas. Este deber viene exigido por el art. 43 de la Constitución española, que consagra el derecho a la protección a la salud y procura la debida atención a las necesidades de salud de la comunidad. La objeción de conciencia del farmacéutico puede entrar en conflicto con este derecho y causar un potencial perjuicio a la salud.

La cuestión acerca de los límites de la objeción de conciencia, con el fin de evitar perjuicios indeseables, no está en absoluto abordada en la sentencia. Podría haberla desarrollado en la argumentación por la que decide no amparar la negativa del farmacéutico a proveerse de preservativos. Es evidente que en lo que respecta a los preservativos hay uno o varios límites a la objeción de conciencia aducida por el farmacéutico sevillano, aunque no sabemos cuál o cuáles después de leer la sentencia. Un criterio-límite es el de la correcta organización de las prestaciones. Este criterio-límite sirve también para abundar en una respuesta a la objeción de no poseer la oficina de farmacia de existencias y la objeción de un farmacéutico a no dispensarlas: la correcta organización de las prestaciones farmacéuticas parece indicar que la objeción de conciencia debe amparar la segunda posibilidad y no la primera.

\section{4. ¿En qué momento nos} encontramos en el debate bioético actual sobre los efectos y consecuencias de la píldora postcoital? ¿La discrepancia científica justifica una

presunción a favor de la objeción de conciencia?

La Resolución de 5 de marzo de 2011 de la Agencia Española de Medicamentos y Productos Sanitarios solamente atribuye al medicamento con el principio activo levonorgestrel el carácter de "medicamento anticonceptivo de emergencia”. Esta formulación no deja duda de que, para el legislador, no se trata de un producto abortivo.

Para el Tribunal Constitucional (Fundamento Jurídico Sexto), la "renuencia del demandante a disponer de profilácticos en su oficina de farmacia no queda amparada" por la objeción de conciencia. No sabemos las razones que sostienen esta afirmación y debemos suponer atrevidamente que los preservativos no poseen el potencial abortivo que sí parece otorgar a la píldora postcoital. Esta suposición significa que para el Tribunal la píldora postcoital no es un medicamento anticonceptivo (como el preservativo), sino algo cualitativamente más (abortivo). Lo que hace es afirmar que no está científicamente demostrado que la píldora postcoital no cause efectos abortivos.

El Tribunal Constitucional enfatiza que la cuestión es relevante y merece su amparo, porque existe una "falta de unanimidad científica respecto a los posibles efectos abortivos de la denominada "píldora del día después". "La existencia de una duda razonable sobre la producción de dichos efectos" (abortivos) plantea la posibilidad de una colisión con la concepción sobre el derecho a la vida del demandante de amparo (Fundamento jurídico cuarto de la sentencia). No es objetivo de este breve análisis desarrollar y exponer las líneas que defiendan médica y científicamente los efectos de inhibición de la implantación del preembrión, los plazos de tiempo en que actúan estos efectos inhibidores, la afectación sobre el embrión implantado, etc.; cuestiones éstas que no me competen tampoco. Por ahora, prefiero remitir al lector a las páginas 138 a 163 del libro de Francesc Abel S.J. Bioética: pasado, presente y futuro que versan sobre "La condición ética y jurídica del embrión humano". Ahí podrá hacerse una cabal idea del reciente status quaestionis al que afecta la píldora postcoital.

El Tribunal Constitucional, ante la duda, provocada por la falta de unanimidad científica, reconoce la objeción de conciencia del farmacéutico utilizando una presunción: 'ante la duda, a favor del objetor'. Sin embargo, echamos de menos en la sentencia un mínimo de prueba pericial sobre la dóxa filosófica, ética, médica y científica de la naturaleza y efectos del principio activo levonorgestrel en el cuerpo de la mujer (véase la ficha técnica) [4].

Resulta estimulante este avance que ha hecho el Tribunal Constitucional, al proponer este modo de presunción para reforzar el derecho a la objeción de conciencia, aunque en el caso concreto de la sentencia lo haya aplicado con poco rigor. Este "criterio favorable al objetor en caso de duda" fortalece sin duda el derecho a la objeción de conciencia.

\section{5. ¿Es la conducta del}

farmacéutico sevillano la de un objetor de conciencia o más bien la de un insumiso, la de un desobediente civil?

Esta pregunta sirve para medir el alcance y los límites, de nuevo, del derecho a la objeción de conciencia. El objetor no cuestiona la norma, plantea una excepción a su cumplimiento personal, acepta que otros la cumplan y exige que se respete su propia excepción. La regulación de la objeción de conciencia no exime sin más del cumplimiento por el objetor 
sino que prevé formas de que se cumpla la norma velando por los derechos de terceros y la correcta organización de los servicios.

Al contrario, el insumiso cuestiona la norma con carácter general. No desea ser meramente eximido, sino que quiere asumir las consecuencias del incumplimiento y aspira a que la sanción por su desobediencia remueva la conciencia social socavando la legitimidad de la obligación impuesta por la ley.

Distinguir entre una conducta y otra supone formular un nuevo límite a la objeción de conciencia: el del cuestionamiento general de la norma. Sólo será objetable el cumplimiento personal, no el cuestionamiento general. Tampoco ahonda el Tribunal Constitucional en esta interesante cuestión, lamentablemente. Queda a cada cual valorar si lo que hacía el farmacéutico sevillano en su negativa era en realidad un ejercicio de desobediencia civil, de insumisión. Y ése es otro tema, aunque con un componente político bastante más profundo, pues el ejercicio de las convicciones religiosas y personales puede tener más sentido transformador desde la desobediencia civil que desde la pura objeción de conciencia.

\section{Referencias bibliográficas}

1. Pleno del Tribunal Constitucional Sentencia 145/2015, de 25 de junio de 2015. Publicada en el Boletín Oficial del Estado núm. 182, de 31 de julio de 2015.

2. Cortes Españolas. Ley 2/2010, de 3 de marzo, de salud sexual y reproductiva y de la interrupción voluntaria del embarazo.

3. Abel i Fabre F. Bioética, orígenes, presente y futuro. Barcelona: Fundación Mapfre; 2001. ISBN 84-7100-799-1.

4. Agencia Española de Medicamentos y Productos Sanitarios [Internet]. Ficha técnica de Norlevo. [Acceso 12/2/2016]. Disponible en: www.aemps.gob.es/cima/ pdfs/ft/67770/FT_67770.pdf 